Check for updates

Cite this: RSC Adv., 2017, 7, 37787

Received 22nd June 2017

Accepted 26th July 2017

DOI: $10.1039 / c 7 r a 06947 b$

rsc.li/rsc-advances

\section{Migration, reactivity, and sulfur tolerance of copper species in SAPO-34 zeolite toward $\mathrm{NO}_{x}$ reduction with ammonia $\uparrow$}

\begin{abstract}
Xuesong Liu, (D)*abd Xiaodong Wu, (D) *b Duan Weng, ${ }^{\mathrm{b}}$ Zhichun $\mathrm{Si}^{\mathrm{c}}$ and Rui Ran ${ }^{\mathrm{b}}$
Cu/SAPO-34 catalysts were prepared by wet impregnation and ion-exchange methods, and both the catalysts were hydrothermally treated at $750{ }^{\circ} \mathrm{C}$ in 10 vol\% $\mathrm{H}_{2} \mathrm{O} /$ air for $24 \mathrm{~h}$. Subsequently, the asreceived and hydrothermally treated catalysts were exposed to a sulfur poisoning treatment at $350{ }^{\circ} \mathrm{C}$ in $100 \mathrm{ppm} \mathrm{SO} / 10$ vol\% $\mathrm{H}_{2} \mathrm{O}$ /air for $24 \mathrm{~h}$ and examined for $\mathrm{NO}_{x}$ conversion. Sulfur poisoning considerably decreased the $\mathrm{NO}_{x}$ conversion efficiency of the catalysts at low temperatures. In contrast, it improved the high-temperature selective catalytic reduction (SCR) activities of the as-received catalysts. The ionexchange-prepared catalysts displayed higher sulfur tolerance than the impregnation-prepared catalysts at $150-350{ }^{\circ} \mathrm{C}$. The electron paramagnetic resonance, X-ray photoelectron spectroscopy, energydispersive $\mathrm{X}$-ray spectroscopy and $\mathrm{H}_{2}$-temperature-programmed reduction results showed that sulfur poisoning significantly influenced the migration of the copper species and thereby the amount of active isolated $\mathrm{Cu}^{2+}$. More dispersed $\mathrm{CuSO}_{4}$ was produced on the ion-exchange-prepared catalysts than on the impregnation-prepared catalysts after sulfur poisoning. The dispersed $\mathrm{CuSO}_{4}$ showed considerably higher SCR activity than the crystalline $\mathrm{CuSO}_{4}$. Both the dispersed $\mathrm{CuSO}_{4}$ and remaining isolated $\mathrm{Cu}^{2+}$ determined the low-temperature SCR behavior of the sulfur-poisoned catalysts.
\end{abstract}

\section{Introduction}

Sulfur is always present in vehicle exhausts arising from residues in the fuel and lubricant oils. It is therefore essential to examine the effect of sulfur on different catalysts involved in $\mathrm{NH}_{3}$-selective catalytic reduction (SCR) after-treatment systems. Despite the considerable reduction in the content of sulfur in diesel fuel in recent years, especially with the implementation of China IV standard diesel in China, sulfur poisoning remains one of the most significant deactivation factors for SCR catalysts employed in heavy-duty diesel motor exhaust after-treatment systems. Although China IV standard diesel contains less than 50 ppm sulfur, the cumulative lifetime exposure of catalysts may amount to kilograms of sulfur.

Several studies ${ }^{1-9}$ have addressed the effects of sulfur poisoning on different $\mathrm{NH}_{3}$-SCR catalysts. Vanadium-based

${ }^{a}$ College of Chemistry and Chemical Engineering, Shaoxing University, Zhejiang 312000, P. R. China. E-mail: xuesongliu@usx.edu.cn

${ }^{b}$ Key Laboratory of Advanced Materials of Ministry of Education, School of Materials Science and Engineering, Tsinghua University, Beijing 100084, P. R. China. E-mail: wuxiaodong@tsinghua.edu.cn

'Advanced Materials Institute, Graduate School at Shenzhen, Tsinghua University, Shenzhen 518055, China

${ }^{d}$ State Key Laboratory of Green Building Materials, China Building Materials Academy, Beijing, 100024, P. R. China

† Electronic supplementary information (ESI) available. See DOI: 10.1039/c7ra06947b catalysts were found to have a greater tolerance toward $\mathrm{SO}_{2}$ poisoning than metal zeolite catalysts. ${ }^{\mathbf{1 , 4 5}}$ Among the zeolitebased catalysts, $\mathrm{Cu}$ zeolites are more sensitive to sulfur dioxide than Fe zeolites, ${ }^{1-3}$ and the deactivation effect is more pronounced at low temperatures. ${ }^{2,4}$

In recent years, $\mathrm{Cu}$-exchanged zeolite catalysts of the chabazite family with unique microporous structures have emerged as a leading candidate among zeolite formulations when compared to $\mathrm{Cu} / \mathrm{ZSM}-5$ and $\mathrm{Cu} /$ beta owing to their superior $\mathrm{NH}_{3}$-SCR activity and prominent hydrothermal stability at $750{ }^{\circ} \mathrm{C}^{10,11}$ Previous research studies ${ }^{12-16}$ demonstrated that isolated $\mathrm{Cu}^{2+}$ species are the active sites for SCR reaction, as determined by extended X-ray absorption fine structure and kinetic tests. Zhang et al. concluded that $\mathrm{SO}_{2}$ inhibited the SCR activity at low temperatures owing to the formation of ammonium sulfates as well as the onset of competitive adsorption between $\mathrm{SO}_{x}$ and $\mathrm{NO}_{x}$ on the Cu sites. ${ }^{17}$ Kumar et al. ${ }^{18}$ compared the effects of $\mathrm{SO}_{2}$ and $\mathrm{SO}_{3}$ on $\mathrm{Cu} / \mathrm{SAPO}-34$ catalyst and found that poisoning with $\mathrm{SO}_{3}$ at $400{ }^{\circ} \mathrm{C}$ resulted in a more severe deactivation when compared with that with $\mathrm{SO}_{2}$. Because of its strong chemical binding strength and the oxidative conditions in diesel exhaust streams, sulfur can react readily with $\mathrm{Cu}$ in a $\mathrm{Cu}$ /zeolite SCR catalyst to form stable $\mathrm{CuSO}_{4}$-like compounds., ${ }^{3,6,7}$ Such a sulfur poisoning phenomenon affects the redox properties of the $\mathrm{Cu}$ sites, severely inhibits NO oxidation and subsequent formation of the adsorbed $\mathrm{NO}_{x}$ 
complex, and ultimately decreases the SCR activity of the catalyst. $^{19,50}$

Although some sulfur poisoning mechanisms of $\mathrm{NH}_{3}-\mathrm{SCR}$ catalysts have been proposed, little information on the effects of sulfur poisoning on different copper species and the location of sulfur has been reported to date.

In the present study, different preparation methods and a hydrothermal treatment were applied to generate different distributions of $\mathrm{Cu}$ species on SAPO-34 support. Various techniques (i.e., X-ray photoelectron spectroscopy, electron paramagnetic resonance, $\mathrm{H}_{2}$ temperature-programmed reduction, and $\mathrm{NH}_{3}$ temperature-programmed desorption) were used to probe the location and state of $\mathrm{Cu}$ species before and after sulfur poisoning. The evolution of different copper species was examined, and their sulfur tolerance was determined, which is rarely reported.

\section{Experimental}

\subsection{Catalyst preparation}

$\mathrm{Cu} / \mathrm{SAPO}-34$ catalysts were synthesized by wet impregnation ${ }^{20}$ and ion-exchange ${ }^{15}$ methods, respectively.

$\mathrm{Cu}\left(\mathrm{CH}_{3} \mathrm{COO}\right)_{2} \cdot \mathrm{H}_{2} \mathrm{O}$ (Ling Feng Chemical Reagent, China) was dissolved in deionized water and mixed with commercial $\mathrm{H}$ SAPO-34 molecular sieve $\left(\mathrm{Al}_{2} \mathrm{O}_{3} / \mathrm{SiO}_{2} / \mathrm{P}_{2} \mathrm{O}_{5}=1: 0.3: 0.8\right)$ powders using a wet impregnation method. The liquid was then dried at $80{ }^{\circ} \mathrm{C}$ using a rotary evaporator employing a vacuum pump. The powders were dried at $100{ }^{\circ} \mathrm{C}$ for $12 \mathrm{~h}$ and calcined at $550{ }^{\circ} \mathrm{C}$ for $4 \mathrm{~h}$, and the as-received catalyst was denoted as CuiF.

The H-SAPO-34 was ion-exchanged using a $\mathrm{NH}_{4} \mathrm{NO}_{3}(99 \%$ $\mathrm{NH}_{4} \mathrm{NO}_{3}$, Aladdin, China) solution at $80{ }^{\circ} \mathrm{C}$ for $2 \mathrm{~h}$ to obtain the $\mathrm{NH}_{4}-\mathrm{SAPO}-34$. Then, the solid was filtered and rinsed with deionized water, and was dried at $100{ }^{\circ} \mathrm{C}$ for $12 \mathrm{~h}$. $\mathrm{Cu}$ ionexchange was performed by mixing the $\mathrm{NH}_{4}-\mathrm{SAPO}-34$ with a $\mathrm{Cu}\left(\mathrm{CH}_{3} \mathrm{COO}\right)_{2}$ (Ling Feng, China) solution at $60{ }^{\circ} \mathrm{C}$ for $4 \mathrm{~h}$. After filtered and washed with deionized water, the powders were dried at $100{ }^{\circ} \mathrm{C}$ for $12 \mathrm{~h}$ and calcined at $550{ }^{\circ} \mathrm{C}$ for $4 \mathrm{~h}$, and the as-received catalyst was denoted as CueF.

The nominal content of $\mathrm{Cu}$ in the catalysts was $2 \mathrm{wt} \%$. Additionally, the as-received catalysts were hydrothermally treated at $750{ }^{\circ} \mathrm{C}$ in 10 vol\% $\mathrm{H}_{2} \mathrm{O}$ /air for $24 \mathrm{~h}$, and the resulting catalysts were denoted as CuiA and CueA, respectively.

In SCR reactions on many catalysts, the $\mathrm{SO}_{2}$ effects involve competitive adsorption of $\mathrm{SO}_{2}$ and the reactants, physical coverage of active sites by ammonium sulfates and formation of active metal sulfates. The last one was irreversible and paid attention to in the present study. To simplify the study, the accumulation of ammonium sulfates and the introduction of $\mathrm{SO}_{2}$ in SCR reaction were not involved. The as-received and hydrothermally treated catalysts were subjected to a sulfur poisoning treatment in $100 \mathrm{ppm} \mathrm{SO}_{2} / 10 \mathrm{vol} \% \mathrm{H}_{2} \mathrm{O} /$ air for $24 \mathrm{~h}$ at $350{ }^{\circ} \mathrm{C}$ which was located within the normal diesel exhaust temperature and commonly applied in the literature, ${ }^{6}$ and the obtained samples were denoted with a "-s" suffix.

For comparison, $\mathrm{CuSO}_{4} / \mathrm{SAPO}-34$ catalysts were synthesized by mechanical mixing and wet impregnation methods using $\mathrm{CuSO}_{4}$ solution as the precursor, and the obtained samples
Table 1 The abbreviations of the samples

\begin{tabular}{|c|c|c|}
\hline \multirow[b]{2}{*}{ Sample } & \multicolumn{2}{|l|}{ Abbreviation } \\
\hline & Unpoisoned & $\begin{array}{l}\text { Sulfur } \\
\text { poisoned }\end{array}$ \\
\hline SAPO-34 support & SAPO-34 & SAPO-34-S \\
\hline Impregnated Cu/SAPO-34, as-received & CuiF & CuiF-s \\
\hline Ion-exchanged $\mathrm{Cu} / \mathrm{SAPO}-34$, as-received & CueF & CueF-s \\
\hline $\begin{array}{l}\text { Impregnated Cu/SAPO-34, } \\
\text { hydrothermally aged }\end{array}$ & CuiA & CuiA-s \\
\hline $\begin{array}{l}\text { Ion-exchanged Cu/SAPO-34, } \\
\text { hydrothermally aged }\end{array}$ & CueA & CueA-s \\
\hline Impregnated $\mathrm{CuSO}_{4} / \mathrm{SAPO}-34$ & - & Cui-s \\
\hline Mechanically mixed $\mathrm{CuSO}_{4} / \mathrm{SAPO}-34$ & - & Cum-s \\
\hline
\end{tabular}

were denoted as Cum-s and Cui-s, respectively. The nominal mass content of $\mathrm{Cu}$ in the catalysts was also $2 \mathrm{wt} \%$. The comparison of sample and abbreviation were listed in Table 1.

\subsection{Activity measurement}

The $\mathrm{NH}_{3}$-SCR activity was evaluated in a fixed bed quartz reactor, and the effluent gases were monitored by infrared spectroscopy (Thermo Nicolet 380). The reaction gas consisted

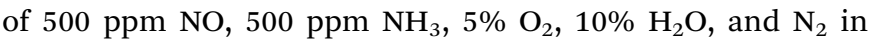
balance. The flow rate of the reaction gas was $1000 \mathrm{~mL} \mathrm{~min}^{-1}$, the amount of catalyst (sieved to 50-80 mesh) used was $300 \mathrm{mg}$, and the gas hourly space velocity was kept at $100000 \mathrm{~h}^{-1}$. The concentration of $\mathrm{NO}_{x}\left(\mathrm{NO}, \mathrm{N}_{2} \mathrm{O}\right.$, and $\left.\mathrm{NO}_{2}\right)$ was detected at the ppm level. The $\mathrm{NO}_{x}$ conversion of the catalysts was calculated using eqn (1):

$$
\begin{aligned}
\mathrm{NO}_{x} \text { conversion }(\%)= & \frac{\mathrm{NO}_{\text {in }}-\mathrm{NO}_{\text {out }}-\mathrm{NO}_{2 \text { out }}-2 \mathrm{~N}_{2} \mathrm{O}_{\text {out }}}{\mathrm{NO}_{\text {in }}} \\
& \times 100,
\end{aligned}
$$

\subsection{Characterization}

X-ray powder diffraction (XRD) patterns were recorded on a diffractometer (D8 ADVANCE, Bruker, Germany) employing $\mathrm{Cu} \mathrm{K} \alpha$ radiation $(\lambda=0.15418 \mathrm{~nm})$. Data were collected in the range of $5^{\circ} \leq 2 \theta \leq 50^{\circ}$ with a scanning velocity of $6^{\circ} \mathrm{min}^{-1}$.

Textural properties were determined by nitrogen physisorption at $-196{ }^{\circ} \mathrm{C}$ using a JW-BK122F (Beijing JWGB, China) instrument. Prior to the measurements, the samples were degassed at $0.01 \mathrm{~Pa}$ at $220{ }^{\circ} \mathrm{C}$. The specific surface area and desorption pore volume were assessed using the BrunauerEmmett-Teller (BET) and Barrett-Joyner-Halenda methods, respectively.

The actual contents of $\mathrm{Cu}, \mathrm{Si}, \mathrm{Al}, \mathrm{P}$ and $\mathrm{S}$ were determined on an Agilent 5100 ICP-OES instrument.

Electron paramagnetic resonance (EPR) spectra in the Xband were recorded on a CW spectrometer JES-FA200 (JEOL) at microwave power of $1 \mathrm{~mW}$, modulation frequency of $100 \mathrm{kHz}$, and central field of $300 \mathrm{mT}$. Before the measurements, the samples were heated in vacuum from room temperature to $100{ }^{\circ} \mathrm{C}$ for $30 \mathrm{~min}$. The samples were then cooled to $-150{ }^{\circ} \mathrm{C}$. 
$\mathrm{Mn}^{2+}$ was used as an external reference sample, and the $g$ value and EPR spectral intensity of $\mathrm{Cu}^{2+}$ were determined.

Transmission electron microscopy (TEM) image and composition of the catalysts were taken on a JEM-2100F (JEOL, Japan) high resolution transmission electron microscope equipped with energy dispersive X-ray spectroscopy (EDX, Oxford EDX System). The catalysts were suspended in ethanol and dispersed over a carbon-coated holey Ni grid with a film prior to measurements.

Hydrogen temperature-programmed reduction $\left(\mathrm{H}_{2}-\mathrm{TPR}\right)$ was performed on a Micromeritics Auto Chem II. Prior to the $\mathrm{H}_{2}$-TPR experiment, the test sample $(50 \mathrm{mg}$ ) was treated with $\mathrm{He}$ at a total flow rate of $50 \mathrm{~mL} \mathrm{~min}{ }^{-1}$ at $300{ }^{\circ} \mathrm{C}$ for $30 \mathrm{~min}$ and subsequently cooled to room temperature and flushed with $\mathrm{He}$ for $10 \mathrm{~min}$. The atmosphere was then changed to $10 \% \mathrm{H}_{2} / \mathrm{Ar}\left(50 \mathrm{~mL} \mathrm{~min}^{-1}\right)$, and the reactor temperature was raised to $600{ }^{\circ} \mathrm{C}$ at a heating rate of $10{ }^{\circ} \mathrm{C} \min ^{-1} \cdot \mathrm{H}_{2}$ consumption during the experiment was monitored with a thermal conductivity detector.

Sulfate decomposition tests were performed using a mass spectrometer (Omni-star TM). In a typical test, the test sample $\left(50 \mathrm{mg}\right.$ ) was treated with $\mathrm{He}$ at a total flow rate of $50 \mathrm{~mL} \mathrm{~min}{ }^{-1}$ at $300{ }^{\circ} \mathrm{C}$ for $30 \mathrm{~min}$ and subsequently cooled to room temperature and flushed with $\mathrm{He}$ for $10 \mathrm{~min}$. Finally, the atmosphere was changed to $10 \% \mathrm{H}_{2} / \mathrm{Ar}\left(50 \mathrm{~mL} \mathrm{~min}^{-1}\right)$, and the reactor temperature was raised to $1000{ }^{\circ} \mathrm{C}$ using a heating rate of $10{ }^{\circ} \mathrm{C} \mathrm{min}{ }^{-1}$. The intensities of the $\mathrm{m} / \mathrm{z}$ ratios $64\left(\mathrm{SO}_{2}\right)$ and 34 $\left(\mathrm{H}_{2} \mathrm{~S}\right)$ in the outlet gas were monitored as a function of temperature.

Ammonia temperature-programmed desorption ( $\left.\mathrm{NH}_{3}-\mathrm{TPD}\right)$ analysis was performed using a TP 5000-II multiple adsorption apparatus (Xianquan, China). The samples ( $\sim 50 \mathrm{mg}$ ) were pretreated in $\mathrm{He}$ at $500{ }^{\circ} \mathrm{C}$ for $30 \mathrm{~min}$. When the temperature decreased to $50{ }^{\circ} \mathrm{C}, \mathrm{NH}_{3}$ was introduced until adsorption on the samples was saturated. The samples were then purged with He to remove residual $\mathrm{NH}_{3}$ from the surface of the samples. The samples were then heated in $\mathrm{He}$ from 100 to $500{ }^{\circ} \mathrm{C}$ at a rate of $10{ }^{\circ} \mathrm{C} \min ^{-1}$ for subsequent $\mathrm{NH}_{3}$ desorption.

The thermal behavior of the catalysts was evaluated on a Mettler Toledo TG/DSC instrument from room temperature to $1000{ }^{\circ} \mathrm{C}$ in $\mathrm{N}_{2}\left(50 \mathrm{~mL} \mathrm{~min}{ }^{-1}\right)$ at a heating rate of $10^{\circ} \mathrm{C} \mathrm{min}^{-1}$. The test powders $(30 \mathrm{mg}$ ) were loaded in individual alumina sample cells.

X-ray photoelectron spectroscopy (XPS) measurements were performed on a Thermofisher ESCALAB 250Xi high performance electron spectrometer using non-monochromated $\mathrm{Al} \mathrm{K} \alpha$ excitation source $(h \nu=1486.6 \mathrm{eV})$. Binding energies were calibrated using the contaminant carbon $(\mathrm{C} 1 \mathrm{~s}=284.6 \mathrm{eV})$.

\section{Results}

\subsection{Structural properties}

The effects of hydrothermal treatment and sulfur poisoning on the structures of the $\mathrm{Cu}$ species and SAPO-34 were investigated by XRD, and the results are shown in Fig. 1. For comparison, the diffraction pattern of SAPO-34 zeolite was included. The diffraction peaks of SAPO-34 were consistent with that of singlephase chabazite. ${ }^{20}$ The chabazite structure of SAPO-34 remained

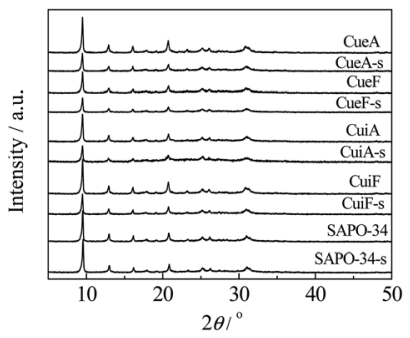

Fig. 1 XRD patterns of the SAPO-34 zeolites and Cu/SAPO-34 catalysts.

intact after copper loading, and no copper-related phases (e.g., $\mathrm{Cu}, \mathrm{Cu}_{2} \mathrm{O}$ and $\mathrm{CuO}$ ) were detected for all the catalysts. These results indicated that the copper species were highly dispersed or existed in the form of $\mathrm{Cu}^{2+}$ ions. ${ }^{15}$ After sulfur poisoning, the intensity of the diffraction peaks of the catalysts decreased, which was mainly attributed to the slight skeleton damage of SAPO-34 upon the treatment. ${ }^{21}$

The specific surface area $\left(S_{\mathrm{BET}}\right)$, micropore surface area $\left(S_{\text {micro }}\right)$, external surface area $\left(S_{\text {ext }}\right)$, and micropore volume of the catalysts were determined and summarized in Table 2. The $S_{\text {ext }}$ of the $\mathrm{Cu} / \mathrm{SAPO}-34$ catalysts were lower than that of the SAPO-34 support owing to coverage of $\mathrm{CuO}$ on the external surface of the zeolite. Interestingly, the $S_{\mathrm{BET}}$ and pore volume of the as-received catalyst CuiF, obtained after copper impregnation of the SAPO-4 support, was higher than those of the support. This increase could be related to the generation of small defects in the SAPO-34 crystals (following $\mathrm{Cu}$ impregnation). ${ }^{22}$ After hydrothermal treatment and sulfur poisoning, the copper species and metal sulfates blocked some of the zeolite channels, thus inducing changes in the textural properties of the zeolite. ${ }^{20,23}$ Moreover, as indicated by the XRD patterns in Fig. 1, skeleton damage of SAPO-34 led to decreases in the BET surface areas and pore volumes of the poisoned catalysts. Nevertheless, these changes of the textural properties for the catalysts should not be important factors responsible for their different catalytic behaviors.

As indicated by the inductively coupled plasma optical emission spectrometry (ICP-OES) results in Table 2, the obtained $\mathrm{Cu}$ contents in the catalysts were very close to the nominal value, and no loss of copper occurred after hydrothermal treatment. The sulfur content in the poisoned $\mathrm{Cu}$ / SAPO-34 catalysts ranged from 0.77 to 0.87 wt $\%$.

\subsection{Catalytic activity}

The temperature dependency of $\mathrm{NO}_{x}$ conversion during the $\mathrm{NH}_{3}$-SCR reaction over the catalysts is shown in Fig. 2. The asreceived $\mathrm{Cu} / \mathrm{SAPO}-34$ catalysts showed superior SCR activity at low temperatures $\left(150-350{ }^{\circ} \mathrm{C}\right)$ as shown in enlarged figure, and the differences were small. The reduced activities at higher temperatures were mainly caused by the competitive reactions between $\mathrm{NH}_{3}$-SCR and $\mathrm{NH}_{3}$ oxidation. ${ }^{\mathbf{2 4 2 5}}$ After the hydrothermal treatment, the catalysts showed high SCR activity at 200-500 ${ }^{\circ} \mathrm{C}$, which are in consistence with the previous report. ${ }^{26}$ Sulfur poisoning reduced the low-temperature $\left(150-350{ }^{\circ} \mathrm{C}\right)$ activities of the catalysts to different degrees; however, it 
Table 2 Textural properties and chemical composition of the samples

\begin{tabular}{|c|c|c|c|c|c|c|c|c|c|}
\hline \multirow[b]{2}{*}{ Sample } & \multirow[b]{2}{*}{$S_{\text {BET }}\left(\mathrm{m}^{2} \mathrm{~g}^{-1}\right)$} & \multirow[b]{2}{*}{$S_{\text {micro }}\left(\mathrm{m}^{2} \mathrm{~g}^{-1}\right)$} & \multirow[b]{2}{*}{$S_{\text {ext }}\left(\mathrm{m}^{2} \mathrm{~g}^{-1}\right)$} & \multirow{2}{*}{$\begin{array}{l}\text { Pore volume } \\
\left(\mathrm{cm}^{3} \mathrm{~g}^{-1}\right)\end{array}$} & \multicolumn{5}{|c|}{ Concentration $^{a}(\mathrm{wt} \%)$} \\
\hline & & & & & $\mathrm{Al}$ & $\mathrm{P}$ & $\mathrm{Si}$ & $\mathrm{Cu}$ & S \\
\hline SAPO-34 & 651 & 607 & 44 & 0.267 & 22 & 21 & 3.9 & - & - \\
\hline SAPO-34-S & 638 & 599 & 39 & 0.262 & 22 & 21 & 3.9 & - & 0.23 \\
\hline CuiF & 676 & 636 & 40 & 0.273 & 22 & 21 & 3.9 & 1.99 & - \\
\hline CuiF-s & 620 & 575 & 45 & 0.253 & 21 & 20 & 3.7 & 1.95 & 0.77 \\
\hline CuiA & 620 & 586 & 34 & 0.241 & 22 & 21 & 3.8 & 1.99 & - \\
\hline CuiA-s & 575 & 525 & 50 & 0.184 & 21 & 20 & 3.7 & 1.96 & 0.81 \\
\hline CueF & 618 & 582 & 36 & 0.238 & 22 & 21 & 3.8 & 2.04 & - \\
\hline CueF-s & 569 & 534 & 35 & 0.219 & 22 & 21 & 3.8 & 2.00 & 0.85 \\
\hline CueA & 621 & 583 & 38 & 0.240 & 22 & 21 & 3.8 & 2.04 & - \\
\hline CueA-s & 560 & 524 & 36 & 0.216 & 22 & 21 & 3.8 & 1.99 & 0.87 \\
\hline
\end{tabular}
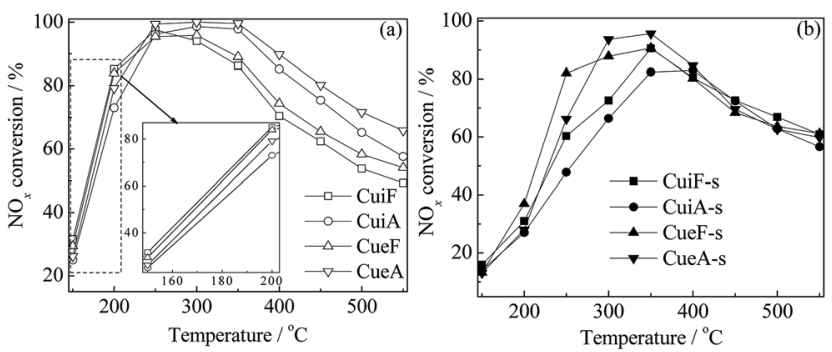

Fig. $2 \mathrm{NH}_{3}-\mathrm{SCR}$ curves of the (a) as-received and hydrothermally treated and (b) poisoned Cu/SAPO-34 catalysts. Reaction conditions: $[\mathrm{NO}]=\left[\mathrm{NH}_{3}\right]=500 \mathrm{ppm}, \mathrm{O}_{2}=5 \%,\left[\mathrm{H}_{2} \mathrm{O}\right]=10 \%, \mathrm{~N}_{2}$ in balance, and $\mathrm{GHSV}=100000 \mathrm{~h}^{-1}$

improved the high-temperature $\left(350-550{ }^{\circ} \mathrm{C}\right)$ activities of the asreceived catalysts. The concentration of $\mathrm{N}_{2} \mathrm{O}$ was always lower than $10 \mathrm{ppm}$ in the whole temperature range (not shown). Such results are discussed further in the following sections.

\section{3. $\quad$ EPR studies}

The hyperfine structure of isolated $\mathrm{Cu}^{2+}$ species was characterized by EPR analysis. In contrast, other copper species do not produce any EPR signals..$^{15}$ Therefore, EPR is an effective method to quantitatively determine the amount of isolated $\mathrm{Cu}^{2+}$ on $\mathrm{Cu}$-zeolite catalysts. Fig. 3 shows the EPR spectra of the nonpoisoned (as-received and hydrothermally treated) and poisoned $\mathrm{Cu} / \mathrm{SAPO}-34$ catalysts. Four adsorption peaks were detected in the parallel region, and a sharp peak was observed in the vertical region. The EPR signals at $g_{\|}=2.392, A_{\|}=12.958$, and $g_{\perp}=2.074 \mathrm{mT}$ could be ascribed to $\mathrm{Cu}^{2+}$ species on the site (I) displaced from the six-ring structure into the ellipsoidal cavity of the SAPO-34 zeolite. ${ }^{26,27}$ Furthermore, the intensity of the hyperfine splitting peaks of the sulfur-poisoned samples was lower, indicating a reduction in the number of isolated $\mathrm{Cu}^{2+}$ active species.

\subsection{EDX studies}

In order to examine the effects of the hydrothermal aging and sulfur poisoning on the distributions of copper species on the external surface of SAPO-34, EDX measurements were carried out based on TEM images and spectra in Fig. S1, $\dagger$ and the results were listed in Table 3. It can be seen that the hydrothermal treatment promoted the migration of $\mathrm{Cu}$ from the zeolite external surface to the ion-exchanged sites, which was similar to our previous report. ${ }^{16}$ After the sulfur poisoning, the surface $\mathrm{Cu}$ concentration increased again for all the catalysts as well as the accumulation of sulfur, suggesting that the sulfur poisoning can provide the driving force for copper migration.

\section{5. $\quad \mathrm{H}_{2}$-TPR studies}

$\mathrm{H}_{2}$-TPR is commonly used for determining types of copper species and the redox properties of catalysts. Fig. S2 $\uparrow$ shows the TPR curves of the unpoisoned $\mathrm{Cu} / \mathrm{SAPO}-34$ catalysts. Four reduction peaks were observed in the temperature range of 50$600{ }^{\circ} \mathrm{C}$. The first peak observed at $100-150{ }^{\circ} \mathrm{C}$ was attributed to the reduction of surface $\mathrm{CuO}$ clusters on the external surface of the zeolite framework, proceeding via a one-step reduction with the stoichiometry of one mole of $\mathrm{H}_{2}$ for one mole of CuO clusters. ${ }^{27}$ The second peak was attributed to the reduction of isolated $\mathrm{Cu}^{2+}$ in the zeolite framework to $\mathrm{Cu}^{+}$. The third peak was attributed to the reduction of $\mathrm{CuO}$ crystallites from $\mathrm{CuO}$ to $\mathrm{Cu}^{0}$. The fourth peak was attributed to the reduction of $\mathrm{Cu}^{+}$to $\mathrm{Cu}^{0}{ }^{11}$ including that of $\mathrm{Cu}^{+}$ions obtained from the reduction of isolated $\mathrm{Cu}^{2+}$ and that of original $\mathrm{Cu}^{+}$ions in the framework of

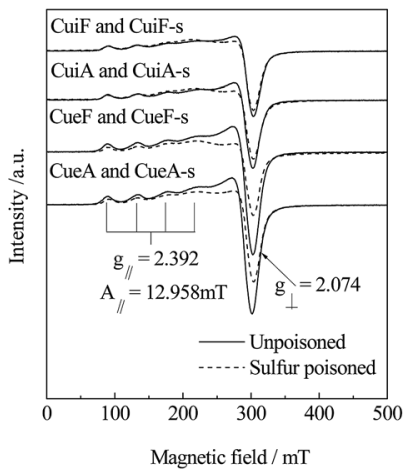

Fig. 3 EPR spectra of the Cu/SAPO -34 catalysts measured at $-150^{\circ} \mathrm{C}$. 
Table 3 Chemical composition of the Cu/SAPO-34 catalysts obtained by EDX

\begin{tabular}{|c|c|c|c|c|c|c|}
\hline \multirow[b]{2}{*}{ Catalysts } & \multicolumn{6}{|c|}{ Concentration (wt\%) } \\
\hline & $\mathrm{O}$ & $\mathrm{Al}$ & $\mathrm{P}$ & $\mathrm{Si}$ & $\mathrm{Cu}$ & S \\
\hline CuiF & 44.09 & 24.98 & 23.82 & 4.25 & 2.86 & - \\
\hline CuiF-s & 46.03 & 23.11 & 22.54 & 4.09 & 3.28 & 0.94 \\
\hline CuiA & 44.23 & 25.06 & 25.30 & 3.84 & 1.57 & - \\
\hline CuiA-s & 45.77 & 22.74 & 23.45 & 3.51 & 4.01 & 0.53 \\
\hline CueF & 46.09 & 23.82 & 23.41 & 3.56 & 3.13 & - \\
\hline CueF-s & 42.87 & 24.30 & 24.04 & 3.26 & 3.65 & 0.93 \\
\hline CueA & 47.60 & 23.32 & 23.42 & 3.70 & 1.96 & - \\
\hline CueA-s & 42.18 & 24.67 & 25.21 & 4.11 & 2.50 & 1.32 \\
\hline
\end{tabular}

SAPO-34. According to the literature, ${ }^{28}$ the isolated $\mathrm{Cu}^{2+}$ ions was reducible in the temperature range $200-300{ }^{\circ} \mathrm{C}$, but the reduction of $\mathrm{Cu}^{+}$ions at the ion-exchange sites to $\mathrm{Cu}^{0}$ occurred at distinctly higher temperatures, or they were too stabile to be reduced in the $\mathrm{H}_{2}$-TPR temperature range. Table 4 lists the amounts of different reducible $\mathrm{Cu}^{x+}$ species on the catalysts based on the TPR curves. The $\mathrm{H}_{2}$ consumption was much less than the theoretical value, even if we assumed that all the copper ions existed as $\mathrm{Cu}^{+}$. This indicated that some copper species ( $\mathrm{Cu}$ ions at the ion-exchange sites) were too stable to be reduced to $\mathrm{Cu}^{0}$ at temperatures below $800{ }^{\circ} \mathrm{C}$. As observed, the isolated $\mathrm{Cu}^{2+}$ ions were more abundant on the ion-exchanged catalysts, and reached the maximum on CueA. Contrarily, more surface $\mathrm{CuO}$ clusters were found on the impregnated catalysts, and reached the maximum on Cuif. Furthermore, the strong interaction of copper ions with the zeolite framework, upon the hydrothermal treatment, produced more reducible copper species and especially isolated $\mathrm{Cu}^{2+}$ ions. ${ }^{29}$

Surface $\mathrm{CuO}$ clusters are more active toward the oxidation of NO to $\mathrm{NO}_{2}$ than isolated $\mathrm{Cu}^{2+}$ ions, ${ }^{30}$ which favor lowtemperature reactions via the so-called fast SCR reaction. ${ }^{20,30}$ In contrast, surface $\mathrm{CuO}$ clusters inhibit the high-temperature SCR activity owing to their high catalytic activity toward $\mathrm{NH}_{3}$ oxidation. ${ }^{20,30}$ The isolated $\mathrm{Cu}$ ions are always active within a wide temperature range $\left(150-550^{\circ} \mathrm{C}\right)$. Hence, the surface $\mathrm{CuO}$ clusters and isolated $\mathrm{Cu}^{2+}$ ions synergistically determine the SCR performance of $\mathrm{Cu} / \mathrm{SAPO}-34$ catalysts, resulting in trends in catalytic activity in two temperature regions. The trend in lowtemperature activity is in good agreement with the amount of surface $\mathrm{CuO}$ clusters as shown in the enlarged figure in Fig. 2a, although the difference is not obvious. For the impregnated catalysts, abundant surface $\mathrm{CuO}$ clusters play a more crucial role in the low temperature range than isolated $\mathrm{Cu}^{2+} \cdot{ }^{30,31}$ Isolated $\mathrm{Cu}^{2+}$ ions are abundant in the ion-exchanged catalysts and dominate the activity at low temperatures. Both types of copper species can act as active sites for the low-temperature SCR reaction. The active surface $\mathrm{CuO}$ clusters is absent in some studies, ${ }^{32,33}$ due to the specific SAPO-34 supports and preparation methods adopted, and the hydrothermal treatment will increase the amount of $\mathrm{Cu}^{2+}$ and improve the activity at low temperatures.

$\mathrm{H}_{2}$-TPR analysis was also conducted on the sulfur-poisoned catalysts. Three peaks of $\mathrm{H}_{2}$ consumption were observed (Fig. 4). The peak observed at the lowest temperature (peak A) was attributed to the reduction of isolated $\mathrm{Cu}^{2+}$ to $\mathrm{Cu}^{+}{ }^{+}{ }^{34,35}$ The peaks observed at $230-350{ }^{\circ} \mathrm{C}$ (peak B) and $350-450{ }^{\circ} \mathrm{C}$ (peak C) were attributed to the reduction of dispersed $\mathrm{CuSO}_{4}$, and overlapping of the reduction of crystalline $\mathrm{CuSO}_{4}$ (ref. 36 and 50) and $\mathrm{Cu}^{+}$to $\mathrm{Cu}^{0}$, respectively. ${ }^{31,50}$ Assignments of these reduction peaks were confirmed by the TPR curves of reference samples Cui-s and Cum-s. Specifically, peak A was absent for these mixed catalysts using $\mathrm{CuSO}_{4}$ as the precursor. Cui-s displayed a dominant peak $\mathrm{B}$, which was assigned to the reduction of dispersed $\mathrm{CuSO}_{4}$. Cum-s displayed a bimodal peak distribution that accounts for the reduction of dispersed $\mathrm{CuSO}_{4}$ and crystalline $\mathrm{CuSO}_{4}$ at 320 and $380{ }^{\circ} \mathrm{C},{ }^{31,36}$ respectively. The reducibility of $\mathrm{CuSO}_{4}$ species followed the order of dispersed $\mathrm{CuSO}_{4}>$ crystalline $\mathrm{CuSO}_{4}$. The results agreed with the XRD results, which indicated that the dispersion of $\mathrm{CuSO}_{4}$ in Cui-s and Cum$\mathrm{s}$ is different. Compared with the unpoisoned catalysts

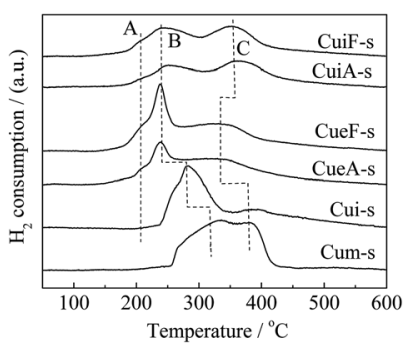

Fig. $4 \mathrm{H}_{2}$-TPR curves of the poisoned catalysts.

Table 4 Amounts of different copper species on the Cu/SAPO-34 catalysts

Amount of reducible copper species ${ }^{b}$ ( $\mu$ mol Cu per g cat.)

\begin{tabular}{|c|c|c|c|c|c|c|}
\hline Sample & $\begin{array}{l}\text { Amount of copper } \\
\text { ( } \mu \text { mol Cu per g cat.) }\end{array}$ & $\begin{array}{l}\text { Surface } \mathrm{CuO} \\
\text { clusters }\end{array}$ & Isolated $\mathrm{Cu}^{2+}$ & $\mathrm{CuO}$ crystallites & $\mathrm{Cu}^{+}$ & Total $^{c}$ \\
\hline CuiF & 310.9 & 47.7 & 30.5 & 61.9 & 56.9 & $140.1(166.5)$ \\
\hline CuiA & 310.9 & 10.9 & 65.3 & 96.8 & 148.3 & $173.0(256.0)$ \\
\hline CueF & 318.8 & 32.9 & 208.1 & 56.0 & 120.6 & $297.0(209.5)$ \\
\hline CueA & 318.8 & 9.9 & 255.1 & 67.2 & 177.4 & $332.2(254.5)$ \\
\hline
\end{tabular}

${ }^{a}$ Calculated based on the ICP results in Table $2 .{ }^{b}$ Obtained by $\mathrm{H}_{2}$-TPR curves. ${ }^{c}$ The data outside and inside the brackets were estimated based on the sum of surface $\mathrm{CuO}$ clusters, isolated $\mathrm{Cu}^{2+}$ and $\mathrm{CuO}$ crystallites (that of surface $\mathrm{CuO}$ clusters, $\mathrm{CuO}$ crystallites and $\mathrm{Cu}^{+}$). 
(Fig. S2 $\dagger$ ), the reduction peak associated with surface $\mathrm{CuO}$ clusters (at 100-150 ${ }^{\circ} \mathrm{C}$ ) disappeared completely after sulfur poisoning owing to accessibility to $\mathrm{SO}_{2}$ and transformation to copper sulfates. In contrast, some isolated copper ions remained as the small pores $(0.43 \mathrm{~nm})$ of SAPO-34 protected the isolated $\mathrm{Cu}^{2+}$ from attack by $\mathrm{SO}_{2}$, which has a similar kinetic diameter of $0.411 \mathrm{~nm} .{ }^{37}$ As determined from the $\mathrm{H}_{2}$-TPR curves, $\mathrm{CuSO}_{4}$ was highly dispersed on the poisoned ion-exchangeprepared catalysts. In contrast, the metal sulfates was much larger on the poisoned impregnation-prepared catalysts, and hence, $\mathrm{CuSO}_{4}$ was not as highly dispersed in the poisoned impregnation-prepared catalysts.

Surface CuO clusters and crystallites are more abundant on the impregnation-prepared catalysts. After sulfur poisoning, surface $\mathrm{CuO}$ clusters and crystallites tended to transform to dispersed $\mathrm{CuSO}_{4}$ and crystalline $\mathrm{CuSO}_{4}$, respectively, and the generated dispersed $\mathrm{CuSO}_{4}$ would sinter to form crystalline $\mathrm{CuSO}_{4}$, too. Thus, it appeared to be easier for surface copper species to form crystalline sulfates upon the sulfur poisoning treatment since they were exposed on the catalyst surface. As shown in Table 4 and Fig. $\mathrm{S} 2, \dagger$ the isolated $\mathrm{Cu}^{2+}$ ions were much more abundant on the ion-exchanged catalysts (CueF and CueA). On the other hand, the reduction peak B of the corresponding sulfated catalysts (CueF-s and CueA-s) in Fig. 4, which was attributed to the reduction of dispersed $\mathrm{CuSO}_{4}$, was much intenser than those of the sulfated impregnated catalysts (CuiFs and CuiA-s). Based on kinetic and thermodynamic theories, it is easier for isolated $\mathrm{Cu}^{2+}$ to migrate onto the catalyst surface to form dispersed $\mathrm{CuSO}_{4}$ than $\mathrm{CuSO}_{4}$ crystallites under the same poisoning treatment condition. Previous studies also have elucidated the impact of sulfur poisoning on $\mathrm{Cu}$ dispersion. Cheng et $a .^{7}{ }^{7}$ used XANES/EXAFS analyses to investigate properties of the copper species in Cu/SAPO-34 before and after sulfur poisoning. The $\mathrm{Cu}$ K-edge XANES spectra for the $\mathrm{Cu} /$ SAPO-34 before and after sulfur poisoning, as well as the spectra for $\mathrm{CuSO}_{4}$ as a reference. The XANES spectra between 8975 and $8985 \mathrm{eV}$ were similar for both the unsulfated and sulfur-poisoned catalysts, but quite different from the spectrum of crystalline $\mathrm{CuSO}_{4}$. This suggests that the sulfate formation resulting from sulfur poisoning does not induce any macroscopic changes in the $\mathrm{Cu}$ species; in other words, $\mathrm{Cu}$ remains in a highly dispersed state as its initial ion-exchange locations. A similar phenomenon was observed by Hamada et al. ${ }^{38}$ over a Cu-ZSM-5 catalyst after $\mathrm{SO}_{2} / \mathrm{O}_{2}$ treatment.

As observed in Fig. 5, a bimodal $\mathrm{SO}_{2}$ release distribution was detected within $250-500{ }^{\circ} \mathrm{C}$ by mass spectrometry analysis. The low-temperature peak was ascribed to the decomposition/ reduction of dispersed $\mathrm{CuSO}_{4}$ was centered at 310 and $330{ }^{\circ} \mathrm{C}$ for the poisoned ion-exchange- and impregnation-prepared catalysts, respectively. The high-temperature peak was located at $380{ }^{\circ} \mathrm{C}$ and ascribed to the decomposition/reduction of crystalline $\mathrm{CuSO}_{4}$. Moreover, the poisoned ion-exchange-prepared catalysts displayed a stronger dispersed $\mathrm{CuSO}_{4}$-related peak. As noted, the temperatures at which the dispersed $\mathrm{CuSO}_{4}$-related $\mathrm{SO}_{2}$ peak was observed were somewhat higher than those of the corresponding $\mathrm{H}_{2}$ peak $\mathrm{B}$. This difference was attributed to the re-adsorption of the $\mathrm{SO}_{2}$ released from the decomposition/

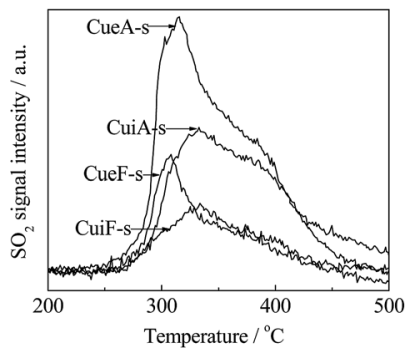

Fig. 5 The outlet $\mathrm{SO}_{2}$ signals detected from the $\mathrm{H}_{2}$-TPR tests of the poisoned catalysts.

reduction of $\mathrm{CuSO}_{4}$ on the catalyst. ${ }^{39,40} \mathrm{No}_{2} \mathrm{~S}$ was detected at 50-1000 ${ }^{\circ} \mathrm{C}$ for all the poisoned catalysts. The formation of elemental sulfur on the catalyst surface cannot be completely excluded or some of the reduction products were not detected by MS, which may be responsible for the differences between the sulfate amounts determined by ICP-OES, TGA and MS. In this sense, the ICP-OES results appear to be more reliable.

\section{6. $\mathrm{NH}_{3}$-TPD studies}

Ammonia is widely used as a probe molecule to identify types of surface acidic sites. ${ }^{41-43}$ In this study, the acid properties of the non-poisoned and poisoned catalysts were studied by $\mathrm{NH}_{3}$-TPD. Fig. 6 shows the $\mathrm{NH}_{3}$-TPD profiles of the different catalysts. Two broad bands at $120-260$ and $320-460{ }^{\circ} \mathrm{C}$ could be observed, which could be deconvoluted into three desorption peaks (A, B, and C). ${ }^{44}$ Peaks $\mathrm{B}$ and $\mathrm{C}$ observed at the higher temperatures could possibly be assigned to structural Brønsted acid sites, which can be correlated to moderate and strong acidity. ${ }^{37,45-48}$ After copper loading, considerable changes in peaks A, B, and C were observed. Peak A could be attributed to the adsorption of $\mathrm{NH}_{3}$ molecules on weak Brønsted acid sites on the zeolite and weak Lewis acid sites related to $\mathrm{Cu}$ species. Peak B was ascribed to structural Brønsted acid sites on the zeolite and moderate Lewis acid sites related to $\mathrm{Cu}$ species. Peak $\mathrm{C}$ was related to the adsorption of $\mathrm{NH}_{3}$ molecules on both strong Brønsted acid sites on the SAPO-34 support and new Lewis acid sites created by the $\mathrm{Cu}$ species. ${ }^{\mathbf{4 1}}$ The assignments of different peaks are supported by the DRIFTS results as shown in Fig. S3. $\dagger$ Table 4 lists the amount of the different acid sites calculated from the $\mathrm{NH}_{3}$-TPD results. As observed, the loading of $\mathrm{Cu}$ reduced the surface acidity

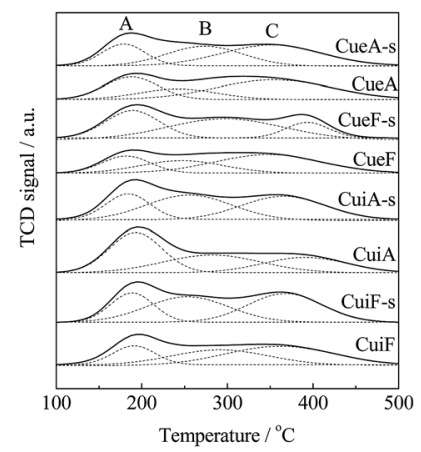

Fig. $6 \mathrm{NH}_{3}$-TPD profiles of the Cu/SAPO-34 catalysts. 
Table 5 Acidity of the Cu/SAPO-34 catalysts and zeolite determined by $\mathrm{NH}_{3}-\mathrm{TPD}$ analysis

\begin{tabular}{lllll}
\hline & \multicolumn{2}{l}{ Acidity $\left(\mathrm{mmol} \mathrm{NH}_{3}\right.$ per g cat. $)$} & \\
\cline { 2 - 5 } Sample & Weak & Moderate & Strong & Total \\
\hline CuiF & 0.0163 & 0.0302 & 0.0425 & 0.0890 \\
CuiF-s & 0.0255 & 0.0424 & 0.0433 & 0.1112 \\
CuiA & 0.0425 & 0.0350 & 0.0260 & 0.1035 \\
CuiA-s & 0.0226 & 0.0443 & 0.0399 & 0.1068 \\
CueF & 0.0166 & 0.0211 & 0.0399 & 0.0776 \\
CueF-s & 0.0298 & 0.0491 & 0.0134 & 0.0923 \\
CueA & 0.0243 & 0.0168 & 0.0453 & 0.0864 \\
CueA-s & 0.0189 & 0.0308 & 0.0417 & 0.0914 \\
SAPO-34 & 0.0356 & 0.0421 & 0.0391 & 0.1168 \\
& & & & \\
\hline
\end{tabular}

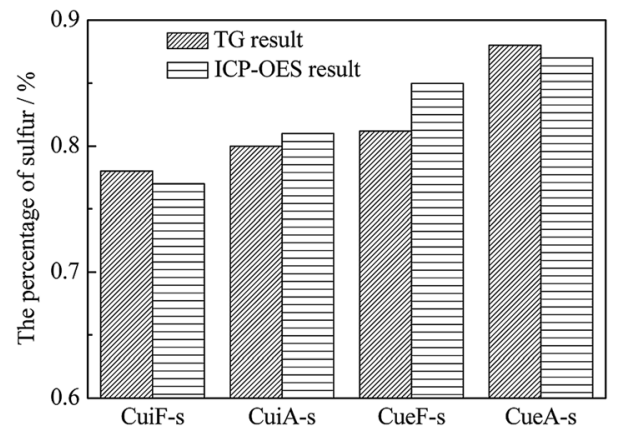

Fig. 7 The percentages of sulfur on the poisoned catalysts determined by TG and ICP-OES analyses.

of HSAPO-34 mainly because of the substitution of the support proton $(-\mathrm{Si}-\mathrm{OH}-\mathrm{Al})$ by $\mathrm{Cu}^{2+}$ ions. Table 5 also shows that more acid sites were created after sulfur poisoning. For the poisoned catalysts, the deposited sulfates could serve as moderate acid sites. Combined with the SCR performance in Fig. 2, the high $\mathrm{NH}_{3}$ adsorption capacity of the poisoned catalysts may facilitate the SCR reaction at high temperatures. When compared with the as-received catalysts, the hydrothermally treated catalysts featured more Lewis acid sites. Sulfur poisoning also led to a decrease in the amount of weak acid sites, which could be related to the reduced amount of Lewis acid sites created by $\mathrm{Cu}$ species owing to the formation of copper sulfates.

Thermogravimetric analysis was conducted on the sulfated catalysts. The percentages of sulfur on the poisoned catalysts were calculated from the thermogravimetric analysis obtained in the temperature range of $450-1000{ }^{\circ} \mathrm{C}$ shown in Fig. 7 (estimated by $\mathrm{SO}_{3}$ ), which decreased in the order of CueA-s $>$ CueF-s $>$ CuiA-s > CuiF-s. The TG results are in good agreement with the ICP-OES results, and minor differences determined by two methods may be caused by the incomplete decomposition or dissolution of some sulfate species. ${ }^{19}$

\section{Discussion}

\subsection{Effects of sulfur poisoning on $\mathrm{Cu}$ species}

The amount of isolated $\mathrm{Cu}^{2+}$ ions was calculated by integrating the EPR curves in the magnetic field range of $0-500 \mathrm{mT}$ and setting the value of CuiF as the standard. As shown in Fig. 8, the amount of isolated $\mathrm{Cu}^{2+}$ decreased after sulfur poisoning to different degrees, and the reduction in the amount of isolated $\mathrm{Cu}^{2+}$ (relative to that prior to sulfur poisoning) decreased in the order of CueA-s $>$ CueF-s $>$ CuiA-s $>$ Cuif-s. This result was consistent with the EPR and $\mathrm{H}_{2}$-TPR results. As the attack of $\mathrm{SO}_{2}$ on the isolated $\mathrm{Cu}^{2+}$ ions is limited owing to the similarity in the pore size of SAPO-34 and kinetic diameter of $\mathrm{SO}_{2}$, the decreased amount of isolated $\mathrm{Cu}^{2+}$ may be due to the migration of isolated $\mathrm{Cu}^{2+}$ to the surface and the formation of the dispersed sulfates.

To confirm the migration of the copper species during the hydrothermal and sulfur poisoning treatments, the $\mathrm{Cu} / \mathrm{Si}$ atomic ratios on the surface and in the bulk were calculated. As listed in Table 6, the as-received catalysts featured a higher $\mathrm{Cu} / \mathrm{Si}$ ratio on the surface than that in the bulk, indicating the enrichment of copper on the external surface of SAPO-34. As noted further, the ion-exchange catalyst CueF featured a higher surface $\mathrm{Cu}$ concentration than the impregnated sample, CuiF. This result was attributed to the relatively low calcination temperature $\left(550^{\circ} \mathrm{C}\right)$ employed, which did not allow sufficient diffusion of surface $\mathrm{CuO}$ into the ion-exchanged sites. After hydrothermal treatment, the surface $\mathrm{Cu} / \mathrm{Si}$ ratios of the catalysts decreased and were lower than the bulk values. This result confirmed the migration of the surface copper ions to the internal region of SAPO-34 zeolite during hydrothermal treatment. ${ }^{16,49}$ The sulfur-poisoned catalysts featured considerably higher surface $\mathrm{Cu} / \mathrm{Si}$ ratios than the non-poisoned catalysts, thus confirming that sulfur poisoning promotes the migration of isolated $\mathrm{Cu}^{2+}$ back to the surface to form copper sulfates. Based on the combined EPR, $\mathrm{H}_{2}$-TPR, EDX and TG results, it is reasonable to suggest that the dispersed $\mathrm{CuSO}_{4}$ species are mainly formed upon migration of isolated $\mathrm{Cu}^{2+}$, whereas the crystalline $\mathrm{CuSO}_{4}$ species are mainly produced from surface $\mathrm{CuO}$ clusters upon sulfation.

\subsection{Effects of sulfur poisoning on $\mathrm{NH}_{3}$-SCR activity}

It has been reported that the types of copper species are critical to the $\mathrm{NH}_{3}$-SCR activity of the zeolite catalysts and the formation of metal sulfates would deactivate the catalysts. Luo et al. ${ }^{29}$ found that both surface $\mathrm{Cu}$ species and isolated $\mathrm{Cu}^{2+}$ were active

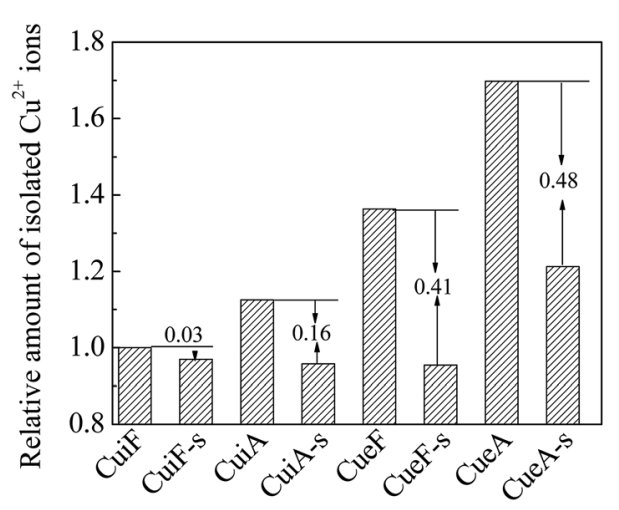

Fig. 8 Relative concentration of isolated $\mathrm{Cu}^{2+}$ ions determined from the EPR results. 
Table 6 Chemical composition of the Cu/SAPO-34 catalysts

\begin{tabular}{lllll}
\hline Sample & $\begin{array}{l}\mathrm{Cu} / \mathrm{Si} \text { in } \\
\text { the bulk }^{a}\end{array}$ & $\begin{array}{l}\mathrm{Cu} / \mathrm{Si} \text { on } \\
\text { the surface }^{b}\end{array}$ & $\begin{array}{l}\mathrm{S} / \mathrm{Si} \text { in } \\
\text { the bulk }^{a}\end{array}$ & $\begin{array}{l}\text { S/Si on } \\
\text { the surface }^{b}\end{array}$ \\
\hline CuiF & 0.23 & 0.29 & - & - \\
CuiF-s & 0.22 & 0.44 & 0.18 & 0.21 \\
CuiA & 0.23 & 0.21 & - & - \\
CuiA-s & 0.22 & 0.30 & 0.19 & 0.19 \\
CueF & 0.23 & 0.33 & - & - \\
CueF-s & 0.22 & 0.48 & 0.20 & 0.16 \\
CueA & 0.23 & 0.22 & - & - \\
CueA-s & 0.22 & 0.34 & 0.20 & 0.11
\end{tabular}

${ }^{a}$ Obtained by ICP-OES. ${ }^{b}$ Obtained by XPS.

for SCR reactions, while surface $\mathrm{Cu}$ species appeared to be more active for $\mathrm{NO}$ oxidation and $\mathrm{NH}_{3}$ oxidation. After sulfur poisoning, both types of $\mathrm{Cu}$ species decreased significantly in the population due to the combination with sulfur. In a recent study by Shen et $a l .{ }^{50}$ both copper sulfate and ammonia sulfate species decrease the SCR reaction rate of the Cu/SAPO-34 catalysts by reducing the number of isolated $\mathrm{Cu}^{2+}$ species, and the copper sulfate is harder to decompose than ammonia sulfate. However, the states of the copper sulfate and their contribution to activity were not involved in these studies.

To clarify the roles of the dispersed $\mathrm{CuSO}_{4}$ and crystalline $\mathrm{CuSO}_{4}$ in $\mathrm{NH}_{3}$-SCR reaction, the $\mathrm{CuSO}_{4} / \mathrm{SAPO}-34$ catalysts were synthesized by mechanical mixing and wet impregnation methods using $\mathrm{CuSO}_{4}$ solution as the precursor. As observed in the XRD patterns in Fig. 9, Cum-s displayed $\mathrm{Cu}\left(\mathrm{SO}_{4}\right) \cdot\left(\mathrm{H}_{2} \mathrm{O}\right)$ diffraction peaks. In contrast, those peaks were absent in Cui-s. These results agreed with the $\mathrm{H}_{2}$-TPR results (Fig. 4), indicating that $\mathrm{CuSO}_{4}$ is finely dispersed on SAPO-34 for Cui-s. As shown in Fig. 10, Cui-s displays much higher SCR activity at low temperatures $\left(150-450{ }^{\circ} \mathrm{C}\right)$ than Cum-s. This demonstrates the dependency of catalytic activity on the dispersion of copper sulfates. It should be noted that the reference catalyst Cui-s even shows higher SCR activity than CuiF-s and CuiA-s in the whole temperature range measured, which may be due to the different status of the impregnated and in situ formed $\mathrm{CuSO}_{4}$, and the detailed mechanism remains to be investigated.

Thus, the SCR reactions at low and high temperatures over the non-poisoned and poisoned $\mathrm{Cu} / \mathrm{SAPO}-34$ catalysts are

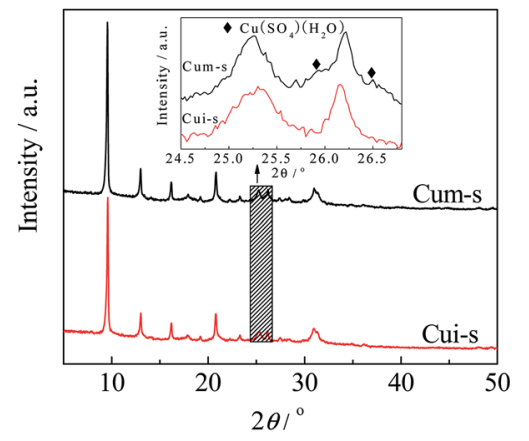

Fig. 9 XRD spectra of $\mathrm{CuSO}_{4} / \mathrm{SAPO}-34$ catalysts.

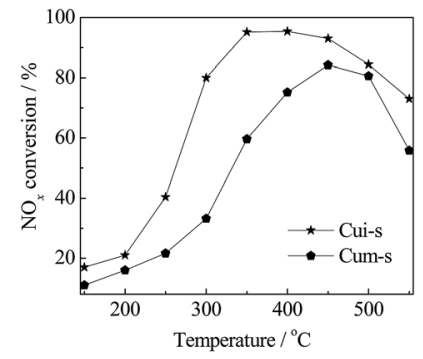

Fig. $10 \mathrm{NH}_{3}-\mathrm{SCR}$ curves of $\mathrm{CuSO}_{4} / \mathrm{SAPO}-34$ catalysts. Reaction conditions: $[\mathrm{NO}]=\left[\mathrm{NH}_{3}\right]=500 \mathrm{ppm}, \mathrm{O}_{2}=5 \%,\left[\mathrm{H}_{2} \mathrm{O}\right]=10 \%, \mathrm{~N}_{2}$ in balance, and GHSV $=100000 \mathrm{~h}^{-1}$.

dominated by different active species as presented in Scheme 1 . Surface $\mathrm{CuO}$ clusters and isolated $\mathrm{Cu}^{2+}$ act synergistically at low temperatures via fast SCR reaction, which occurs mainly on isolated $\mathrm{Cu}^{2+}$ active sites with $\mathrm{NO}_{2}$ generated from the oxidation of $\mathrm{NO}$ on surface $\mathrm{CuO}$ clusters. Upon hydrothermal treatment, a decrease in the amount of surface CuO clusters is observed, which leads to reduced low-temperature activities. At high temperatures, the competitive oxidation of $\mathrm{NH}_{3}$ is weakened via sintering of the surface $\mathrm{CuO}$ clusters to $\mathrm{CuO}$ crystallites, resulting in improved high-temperature SCR activities. In this temperature range, the isolated $\mathrm{Cu}^{2+}$ ions serve as main active sites via the standard SCR reaction. For the sulfur-poisoned catalysts, the catalytic activity depends not only on the sulfur loading but also on the dispersion of the generated $\mathrm{CuSO}_{4}$. As shown in Fig. 10, the dispersed $\mathrm{CuSO}_{4}$ species on Cui-s show much higher activity than the crystalline $\mathrm{CuSO}_{4}$ on Cum-s with the same sulfur loading. Based on the $\mathrm{H}_{2}$-TPR result, the migrated isolated $\mathrm{Cu}^{2+}$ tends to form dispersed $\mathrm{CuSO}_{4}$ species, which are more active for SCR reaction, on the ion-exchanged catalysts after sulfur poisoning. Meanwhile, the surface $\mathrm{CuO}$ clusters and crystallites tend to produce crystalline $\mathrm{CuSO}_{4}$ species, which are less active for $\mathrm{NH}_{3}$-SCR. The intensity of reduction peak of dispersed $\mathrm{CuSO}_{4}$ follows the sequence of

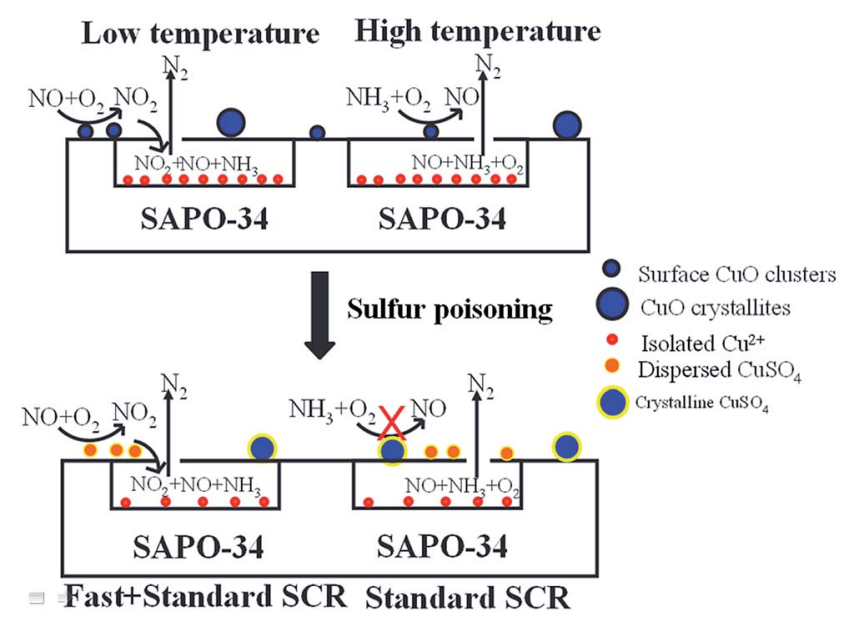

Scheme 1 Roles of different copper species on the non-poisoned and poisoned $\mathrm{Cu} / \mathrm{SAPO}-34$ catalysts in $\mathrm{NH}_{3}-\mathrm{SCR}$ reactions at different temperatures. 
CueF-s > CueA-s > CuiF-s > CuiA-s, which is in good consistence with the low-temperature activity of the sulfated catalysts. Additionally, the sulfur poisoning improves the hightemperature activities of the as-received catalysts by inhibiting $\mathrm{NH}_{3}$ oxidation.

\section{Conclusions}

The application of different preparation methods and the hydrothermal treatment in this work allowed us to obtain different distributions of $\mathrm{Cu}$ species on a zeolite support, and the catalytic activities and sulfur tolerance of those copper species were examined. Sulfur poisoning was found to promote the migration of isolated $\mathrm{Cu}^{2+}$ back to the surface as highly dispersed $\mathrm{CuSO}_{4}$, and the small pores of SAPO-34 appeared to protect the isolated $\mathrm{Cu}^{2+}$ from attack by $\mathrm{SO}_{2}$ to some extent. Crystalline $\mathrm{CuSO}_{4}$ formed mainly from sulfation of surface $\mathrm{CuO}$ clusters and crystallites, and contributed little to the lowtemperature SCR activity. As a result, the operation window of the $\mathrm{Cu} / \mathrm{SAPO}-34$ catalysts shifted toward high temperatures after exposure in $100 \mathrm{ppm} \mathrm{SO}_{2}$ at $350{ }^{\circ} \mathrm{C}$ for $24 \mathrm{~h}$. The migration of copper was observed by XPS and EDX analysis, and a possible mechanism of $\mathrm{Cu}$ migration in sulfur poisoning was proposed on the basis of this observation.

The present study allowed us to learn the relationship between the formation of copper sulfates and the active copper species upon sulfur poisoning, and the contribution of $\mathrm{CuSO}_{4}$ in different dispersion states to the $\mathrm{NH}_{3}$-SCR activity. It provided a strategy to develop anti-sulfur $\operatorname{deNO}_{x}$ catalysts for industrial applications.

\section{Acknowledgements}

The authors acknowledge financial support from the National Natural Science Foundation of China (No. 51372137), Ministry of Science and Technology, PR China (No. 2016YFE0126600), Shaoxing University (No. 2016LG1001), Key Laboratory of Advanced Materials of Ministry of Education of Tsinghua University (2016AML01), the National Key R\&D Program of China (No. 2017YFC0210701) and JCYJ20140417115840287.

\section{References}

1 S. J. Schmieg and J. Lee, SAE Tech. Pap. Ser., 2005, DOI: 10.4271/2005-01-3881.

2 G. Cavataio, J. Girard, J. E. Patterson, C. Montreuil, Y. Cheng and C. K. Lambert, SAE Int., [Spec. Publ.] SP, 2007, DOI: 10.4271/2007-01-1575.

3 Y. Cheng, C. Montreuil, G. Cavataio and C. Lambert, SAE Int., [Spec. Publ.] SP, 2008, 1, 471-476.

4 J. W. Girard, C. Montreuil, J. Kim, G. Cavataio and C. Lambert, SAE Int., [Spec. Publ.] SP, 2008, 1, 488-494.

5 J. A. Ura, J. Girard, G. Cavataio, C. Montreuil and C. Lambert, SAE Int., [Spec. Publ.] SP, 2009, DOI: 10.4271/2009-01-0625.

6 Y. Cheng, C. Montreuil, G. Cavataio and C. Lambert, SAE Int., [Spec. Publ.] SP, 2009, DOI: 10.4271/2009-01-0898.
7 Y. Cheng, C. Lambert, D. H. Kim, J. H. Kwak, S. J. Cho and C. H. F. Peden, Catal. Today, 2010, 151, 266-270.

8 M. Castagnola, J. Caserta, S. Chatterjee, H. Chen, R. Conway, J. Fedeyko, W. Klink, P. Markatou, S. Shah and A. Walker, SAE Int., [Spec. Publ.] SP, 2011, DOI: 10.4271/2011-01-1329.

9 A. Kumar, M. A. Smith, K. Kamasamudram, N. W. Currier, H. An and A. Yezerets, Catal. Today, 2014, 231, 75-82.

10 J. H. Kwak, R. G. Tonkyn, D. H. Kim, J. Szanyi and C. H. F. Peden, J. Catal., 2010, 275, 187-190.

11 P. G. Blakeman, E. M. Burkholder, H. Y. Chen, J. E. Collier, J. M. Fedeyko, H. Jobson and R. R. Rajaram, Catal. Today, 2014, 231, 56-63.

12 D. W. Fickel, E. D'Addio, J. A. Lauterbach and R. F. Lobo, Appl. Catal., B, 2011, 102, 441-448.

13 S. T. Korhonen, D. W. Fickel, R. F. Lobo, B. M. Weckhuysen and A. M. Beale, Chem. Commun., 2011, 47, 800-802.

14 F. Gao, E. D. Walter, N. M. Washton, J. Szanyi and C. H. F. Peden, ACS Catal., 2013, 3, 2083-2093.

15 J. J. Xue, X. Q. Wang, G. S. Qi, J. Wang, M. Q. Shen and W. Li, J. Catal., 2013, 297, 56-64.

16 L. Wang, J. R. Gaudet, W. Li and D. Weng, J. Catal., 2013, 306, 68-77.

17 L. Zhang, D. Wang, Y. Liu, K. Kamasamudram, J. H. Li and W. L. Epling, Appl. Catal., B, 2014, 156-157, 371-377.

18 A. Kumar, M. A. Smith, K. Kamasamudram, N. W. Currier, H. An and A. Yezerets, Catal. Today, 2014, 231, 75-82.

19 X. S. Liu, X. D. Wu, D. Weng and Z. C. Si, Catal. Commun., 2015, 59, 35-39.

20 J. Tan, Z. M. Liu, X. H. Bao, X. C. Liu, X. W. Han, C. Q. He and R. S. Zhai, Microporous Mesoporous Mater., 2002, 53, 97-108.

21 C. D. Yan, H. Cheng, Z. S. Yuan and S. D. Wang, Environ. Technol., 2015, 36, 169-177.

22 J. Ma, Z. C. Si, D. Weng, X. D. Wu and Y. Ma, Chem. Eng. J., 2015, 267, 191-200.

23 F. Bin, C. L. Song, G. Lv, J. N. Song, S. H. Wu and X. D. Li, Appl. Catal., B, 2014, 150-151, 532-543.

24 L. Wang, W. Li, G. S. Qi and D. Weng, J. Catal., 2012, 289, 2129.

25 J. Wang, T. Yu, X. Q. Wang, G. S. Qi, J. J. Xue, M. Q. Shen and W. Li, Appl. Catal., B, 2012, 127, 137-147.

26 L. Ma, Y. S. Cheng, G. V. Cavataio, R. W. McCabe, L. X. Fu and J. H. Li, Chem. Eng. J., 2013, 225, 323-330.

27 M. Calligaris and G. Nardin, Zeolites, 1982, 2, 200-204.

28 M. Richter, M. J. G. Fait, R. Eckelt, M. Schneider, J. Radnik, D. Heidemann and R. Fricke, J. Catal., 2007, 245, 11-24.

29 J. Y. Luo, D. Wang, A. Kumar, J. H. Li, K. Kamasamudram, N. Currier and A. Yezerets, Catal. Today, 2016, 267, 3-9.

30 F. Liu and H. He, J. Phys. Chem. C, 2010, 114, 1692916936.

31 B. Pereda-Ayo, U. D. L. Torre, M. J. Illán-Gómez, A. BuenoLópez and J. R. González-Velasco, Appl. Catal., B, 2014, 147, 420-428.

32 D. Wang, Y. Jangjou, Y. Liu, M. K. Sharma, J. Y. Luo, J. H. Li, K. Kamasamudram and W. S. Epling, Appl. Catal., B, 2015, 165, 438-445.

33 W. K. Su, Z. G. Li, Y. Peng and J. H. Li, Phys. Chem. Chem. Phys., 2015, 17, 29142-29149. 
View Article Online

RSC Advances

Paper

34 C. Torre-Abreu, M. F. Ribeiro, C. Henriques and G. Delahay, Appl. Catal., B, 1997, 14, 261-272.

35 A. Sultana, T. Nanba, M. Haneda, M. Sasaki and H. Hamad, Appl. Catal., B, 2010, 101, 61-67.

36 B. Kartheuser, B. K. Hodnett, A. Riva, G. Centi, H. Matralis, M. Ruwet, P. Grange and N. Passarini, Ind. Eng. Chem. Res., 1991, 30, 2105-2113.

37 J. R. Li, R. J. Kuppler and H. C. Zhou, Chem. Soc. Rev., 2009, 38, 1477-1504.

38 H. Hamada, N. Matsubayashi, H. Shimada, Y. Kintaichi, T. Ito and A. Nishijima, Catal. Lett., 1990, 5, 189-196.

39 Y. J. Shi, H. Shu, Y. H. Zhang, H. M. Fan, Y. P. Zhang and L. J. Yang, Fuel Process. Technol., 2016, 150, 141-147.

40 S. Kikuyama, A. Miura, R. Kikuchi, T. Takeguchi and K. Eguchi, Appl. Catal., A, 2004, 259, 191-197.

41 S. Brandenberger, O. Kröcher, A. Wokaun, A. Tissler and R. Althoff, J. Catal., 2009, 268, 297-306.

42 M. Schwidder, M. S. Kumar, U. Bentrup, J. Pérez-Ramírez, A. Brückner and W. Grünert, Microporous Mesoporous Mater., 2008, 111, 124-133.
43 R. Q. Long and R. T. Yang, J. Catal., 2001, 198, 20-28.

44 D. Z. Zhang, Y. X. Wei, L. Xu, F. X. Chang, Z. Y. Liu, S. H. Meng, B. L. Su and Z. M. Liu, Microporous Mesoporous Mater., 2008, 116, 684-692.

45 A. Izadbakhsh, F. Farhadi, F. Khorasheh, S. Sahebdelfar, M. Asadi and Y. Z. Feng, Appl. Catal., A, 2009, 364, 48-56.

46 G. A. V. Martins, G. Berlier, S. Coluccia, H. O. Pastore, G. B. Superti, G. Gatti and L. Marchese, J. Phys. Chem. C, 2007, 111, 330-339.

47 G. A. V. Martins, G. Berlier, C. Bisio, S. Coluccia, H. O. Pastore and L. Marchese, J. Phys. Chem. C, 2008, 112, 7193-7200.

48 S. Kieger, G. Delahay, B. Coq and B. Neveu, J. Catal., 1999, 183, 267-280.

49 P. N. R. Vennestrøm, A. Katerinopoulou, R. R. Tiruvalam, A. Kustov, P. G. Moses, P. Concepcion and A. Corma, ACS Catal., 2013, 3, 2158-2161.

50 C. Wang, J. Wang, J. Q. Wang, T. Yu, M. Q. Shen, W. L. Wang and W. Li, Appl. Catal., B, 2017, 204, 239-249.

37796

| RSC Adv., 2017, 7, 37787-37796

This journal is (๑) The Royal Society of Chemistry 2017 